\title{
Form Follows Function? Re-questioning the Dilemma of Form vs Function in Contemporary Egyptian Architecture
}

\author{
Karim Kesseiba \\ Faculty of Engineering, Architecture Department, Cairo University
}

\begin{abstract}
Based on the debate continuously raised by architects and theorists regarding the dilemma of "form Vs function", it is important to reflect on the issue in regards of contemporary architecture. Stemming from Le Corbusier's manifesto, "The house is a machine to live in", many interpretations have been made, with one group arguing the importance of demolishing all aspects other than functionality when dealing with an architectural addition to the built environment. The other group adopt the philosophy that "International Architecture" was tailored for a specific time, which has to be dir-regarded now in order to fulfill contemporary architectural needs. The debate which the paper will discuss is based on understanding the origins from which the competition between form and functions stemmed. The paper also questions whether form is currently a function in the era of Globalization in the shadows of branding and starchitects signature designs. This debate will be reflected on major iconic buildings in Egypt; The Grand Egyptian Museum, Museum of Egyptian Civilization and Alexandria Bibliotheca. Those three cases were specifically selected since they were major state-led competitions which influenced the trends of architecture in Egypt for decades. The methodology of the paper is based on primarily explaining the origins of the manifestos by pioneer architects calling for the victory of function over form. Following that, a discussion based on critical observations from contemporary architecture will be presented to show how form is currently considered a function, especially when politicians aim to produce iconic architecture. Finally, the three case studies will be analyzed according to the relevance of form to function and how the iconic effect produced influences after completion. The case study will demonstrate that form and function are the two sides of one coin, and instead of urging to prove one is prior to the other, it is more important fulfill what the goals of the architectural product.
\end{abstract}

Keywords: Contemporary architecture; form follows function; Egyptian Architecture.

\section{Introduction}

The paper raises the long debate between architects around whether form follows function or the contrary. This debate is raised here from a different perspective relevant to the age of globalization, especially in the shadows of iconic effects of consumerism architecture. From this point of view, major state-led architectural projects are re-interpreted in the Egyptian context, in order to relate the selection as well as implementation of the projects with regard to the previous debate. This is important in order to understand the state of contemporary architecture in Egypt which is highly influenced by the three selected projects, Alexandria Library, The Grand Egyptian Museum and The National Museum for Egyptian Civilization. The methodology used in the paper is first to present the debate around the supremacy of form over function or the contrary, after that analysis of the impact of globalization and iconism on this debate. The three local cases are then analyzed based on the theoretical debate to relate to the state of contemporary Egyptian architecture.

\section{Review of the Origins of the Debate between Form and Function in Architecture}

Form follows function is one of the most famous concepts of "modern architecture". As Cruz (2012) argues, this concept symbolizes modern architecture's ascendancy and its decline. The former is assumed when Sullivan manifested in 1896, "Form ever follows function, ..., this is the law", and the latter when Venturi's postmodern theories turned away from modern functionalism by declaring, "We no longer argue over the primacy of form or function (which follows which)?".

Sullivan first presented his arguments that form follows function in 1896. Sullivan's objective in the essay was to answer the question: "How do you give form to something that has never existed before?" He did not mean give form to a specific 
building or an individual design project but to a functional building type - the modern high-rise office building (i.e., the skyscraper). Sullivan thought that social conditions had granted architecture a historic privilege, a task worthy of the architects who first built the Greek temples or Gothic cathedrals, and equal only to architecture as a living art, (Cruz, 2012).

From this regard, Raof (2001) exposes the twentieth-century architecture was influenced by the single analogy referenced to Le Corbusier. He proposed that 'the building is a machine for living in'. However, she argues that a building is very different because, although it is true that it can be controlled by its occupants, the driving force that acts upon the building to create comfort and shelter is the climate and its weather, neither of which can be controlled, predicted or turned on and off. Machines are fixed, static objects, amenable to scientific assessment. Buildings are part of a complex interaction between people, the buildings themselves, the climate and the environment, (Roaf, 2001).

It is important in this respect to associate the inter-relation between the debated slogan of "form follows function" to the new trend of "Globalization". As a matter of fact, since the early twentieth century, architects have sought to link design symbolically to express a particular analysis of society and its future direction. This analysis has often been technological, but it has also been spiritual, psychological and even cosmological. But this view can be reversed; society can be made a mirror to architecture. In addition to this, in architecture, the historical development of globalization corresponded very closely to the ascendancy of Modernism. Founding Modernist ideals had always been global in ambition. In 1919 Gropius predicted, "One day there will be a worldview, and then there will also be its sign, its crystal - architecture." By 1932 it had been identified as the "International Style" and, although this was really a development of "parallel experiments" between nations, it was presented as a "contemporary style, which exists throughout the world, ..., unified and inclusive." By 1948, the year the foundations of globalization were finally laid, Modernism had so obliterated traditional architecture that it came to be described as simply "modern". Finally, Adam (2008) adds that Modernism was a north-Atlantic cultural phenomenon. It was based on the ideals of the same Western Enlightenment thinking that informed globalization: rationality, scientific innovation, progress and the end of tradition.

\section{Analysis: Globalization Effects on Architecture; is Form a new Function in Contemporary Architecture}

As Ren (2008) presents, in the age of globalization, state politicians and bureaucrats have increasingly adopted a global architectural language to rebrand their cities and nations. Although using prominent architects for place marketing is not an entirely new phenomenon, it has taken on a new significance in degree, if not in kind, as cities compete for international recognition and investment.

Sklair (2006) also assumes that the 'starchitects' responsible for designing major iconic statements express much of architecture's paradoxical autonomy, as they have the closest links with the capitalist class. The paradoxical 'autonomy' of those architects is expressed in the landmark commissions, in which the architects seem to struggle over symbolic values rather than politics or economics.

Since the 1970s, cities have been transformed from production sites into consumption sites with strong business service and entertainment functions. In the strong competition between nations, local governments have increasingly employed the strategy of hosting mega events and constructing state-led architectural projects to create a positive urban image to attract residents, visitors, and investment. In the process, signature designs from internationally prominent architects are especially sought after by local private and public clients in order to put their cities on the iconic architectural map. In the past two decades, a large number of high-profile architectural projects have been built in many global and globalizing cities, to list but few, Guggenheim Bilbao Museum in Spain, The Jewish Museum in Berlin and Opera Sydney, (Ren, 2008).

Strom (2002) also argues that the attributes the construction of iconic museums add to the increasingly important role of consumption in urban economies, the financial imperatives of cultural institutions in the new market economy, and the blurring boundary between low and high culture. Sklair (2006) further connects the production, marketing, and consumption of iconic architecture to the agents of the transnational capitalist class.According to Sklair (2006), the transnational capitalist class in and around architecture include multinational architectural firms with great delivery capacity, globalizing politicians and bureaucrats who commission and regulate architectural projects, professionals in the engineering, finance, and real estate sectors, as well as merchants and media, who are responsible for the marketing and consumption of architecture. Sklair (2006) argues that in the global era architecture tends to be driven by the transnational capitalist class of the corporate interest and by the cultural ideology of global consumerism.

Although many have examined the economic imperatives and impact of iconic architectural projects, social scientists have just begun to explore the linkage between nationalism, political identity, and construction of architectural projects under 
conditions of globalization. McNeill (2000) examines the impact of globalization on European territorial politics by analyzing the debates about the opening of the Frank Ghery's Guggenheim Museum in Bilbao. He argues that the construction of the Guggenheim Museum is not only an economic initiative to revitalize Bilbao's de-industrialized urban economy, but also part of the political maneuver by the ruling party in the Basque region to compete with other oppositional institutions and to enhance its relative strength within Spain. Thus, architectural form in this sense is used for an important economic and political image oriented function.

Frampton (1991) observes that the quest for media attention, leads to a context of 'over-aestheticisation' in architecture, in which architects pursue a "succession of stylistic tropes that leave no image unconsumed, so that the entire field becomes flooded with an endless proliferation of images, ..., increasingly designed for their photogenic effect ". This is highly relevant in the competition of the Alexandria Library, to be discussed in the next part of the analysis, where the entries, especially the winning entry, were flooded with metaphoric images related to the resurrection of knowledge as well as contextual metaphors. This image-oriented approach was again present in the Egyptian entries of the Grand Egyptian Museum reflecting the fascination with the creation of image-architecture, argued to create icons which would attract international architectural attention.

\section{Local Case Studies Selection and Analysis Criteria}

The selection of the case studies in the local case is based upon their important role in the Contemporary Egyptian Architecture. The three cases selected are the Alexandria Bibliotheca, the Grand Egyptian Museum and the National Museum of Egyptian Civilization. They all represent major state-led commissions, in which the architectural image was used politically to place the cities where the projects are implemented on the iconic architectural map. The analysis is based on the architectural concept of the project, whether the project achieved an icon or not and the role of the governmental support to the success of the project.

\subsection{Alexandria Bibliotheca:}

The consequent "success" of the iconic projects; to list but few; Opera Sydney, Centre Pompidou, The Jewish Museum in Berlin, led many cities all over the world, to replicate the experience in an attempt to achieve the same "iconic city effect", such as the current local case in Egypt. It can be observed that most state led projects tend to adopt the iconic and stararchitects' systems, yet, more precisely those with a metaphoric dimension, in order to attract international attention and increase funds and external financial support. This was the case in the competition for the Library of Alexandria, where the jury stated clearly that the reason for selecting the first runner-up was the iconic effect it would provide to the city of Alexandria resembling that created by Opera Sydney, neglecting all the calls concerning the adequacy of the design to the economic and technical abilities of a developing country such as Egypt. This looked for icon was used as a fundraising tool by the former political regime, which collected donations from several countries under the cover of the Library. However, as Amin (2012) argues, the series of competitions in Egypt were suspiciously led by the former regime, without clear guidelines for selection, nor clear visions for implementation, leaving much floor for corruption and misuse of the Egyptian competition process.

The competition was originally initiated in 1974, when the University of Alexandria started internal research work to investigate the process and benefits of the library both on the national and international scales. After completing the research, the idea gained a lot of attention and enthusiasm from the Egyptian Government, as well as from the UNESCO and the Program of Development in the United Nations. Then, in June 1988, the project gained the approval from the government, and in September 1988, the international competitions was announced, open to all architects from all parts of the world, and issued under the supervision of the UIA. The competition attracted almost 524 entries from various parts of the world, of which only 24 Egyptian architects presented entries. The site chosen for the new library lies adjacent to the approximate location of the ancient one where a Conference Centre was already present. The land assigned has the area of 40,000 msq, in the heart of the city, directly located in front of the Mediterranean Sea, thus needing special treatment due to the sensitive context.

The jury took into considerations while choosing the winning entries the sensitivity of the location and the value of the rebirth of the old library, thus dealing with the issues of regeneration of an old icon, not only important locally but also internationally. Taking into consideration the plurality of architectural trends at that time, the chairperson exposed that the jury was searching for a design that reflects the contemporary architecture of the 20th century, yet at the same time preserve the 
relations with the past. It was required to search for an icon, which would provide the library with its required unique identity, not a replica of any other style or historic building, so that its value would extend for ages to come.

The first prize winner provided the jury with its required image in the form of the direct metaphor used in the great tilted sun that rises up from the ground, in addition to using the external wall of the inverted cone mass as a huge stone inscription board, which includes all calligraphy from various civilizations, in a clear reflection to the universality of cultures adopted by the Bibliotheca (fig. 1). It has to be taken into consideration that only the entry by the 1st prize winner included such direct metaphorical signs, which was the main reason for selection from the jury's part.

The debates raised were mainly between two groups, one supporting the selected proposal, regarding it a major change in the course of contemporary Egyptian architecture, and in the international trends as well. Accordingly, any construction or economic difficulties have to be disregarded for the sake of achieving such a building that will turn into a national icon and a symbol for Egypt as a whole. Moreover, the supporters accuse those rejecting the idea that they eventually do not understand the new language presented in the proposal, and only look from a very narrow angle, not grasping the whole image as it should be. They regard the proposal as one that succeeded in solving the long debated issue of preserving national identities while using the era's technologies and concepts, while the rejecters are not up to accepting new technologies and contemporary architecture and want to stick to old traditional ways of thinking as well as building.

On the other hand, the rejecters accused the project of not fitting into the assigned function, and perhaps the proposal is ideal for an exhibition, or even a sports arena but not for library. Moreover, they presented a point of view which is the disassociation between the form of the building and its meaning, recalling that the sun metaphor of the building has nothing to do with the Egyptian identity, and were never a symbol for Egypt or its civilization. Besides, even if the metaphor was accepted, it will not be appreciated or even understood, unlike that of Opera Sydney which the supporters provide as an example, since most of the building will be immersed under the ground, and the image and concept required would not be understood, except upon explaining.

On the other side, the opposers presented the claim that the introduction of the new contemporary mechanisms in this project will not really have an impact on the prosper of the Egyptian architecture, since all the technologies, mechanisms, and even labor would be imported from outside, which means working in an island that would not benefit Egypt or the Egyptians, but increase their consumer qualities only.

\subsection{Grand Egyptian Museum:}

The competition for the Grand Egyptian Museum was initiated in January 2002, under full governmental support. The competition decided upon was an international one, open to all architects around the world and organized under the supervision of the UNESCO and the UIA. The client for the museum was the Egyptian Ministry of Culture.

The location of the museum lies in a unique site neighboring the Pyramids of Giza. The project is to be constructed near the Giza Pyramids belonging to a larger archeological area, precisely to the "UNESCO World Heritage Site: Memphis and its Necropolis", which extends in a north-south direction for about $30 \mathrm{~km}$ from Abu Rawash to Dahshour including Abu Ghorab, Abu Sir and Saqqara archeological areas.

The first-prize winner, Heneghan Peng, (fig. 2), was the only one who utilized the Pyramids' visual presence to the fullest as argued by the jury. The concept of maximizing 'view' is strongly felt and consistently practiced throughout the program logistics. The museum design is structured totally along sight lines leading to the Pyramids. This is not just through the organization of geometry, but also through the spatial experience. It is felt by visitors reaching the permanent exhibition area. This floor is above the ground parceled into five thematic zones of the museum program with all main thorough-fares leading to the Pyramids' view.

The proposal also aimed to form a new "edge" to the Plateau, by creating a gentle slope as a thin veil of translucent stone structured by fractal geometry opening and closing like folds within the desert sand. The newly inscribed surface of translucent stone constructs a dynamic identity, yet from within the museum this surface traces a new visual trajectory towards the pyramids. The wall of the museum can be understood as a rhythm of structural (physical) and spatial (effective) folds within the plateau face, "architecturalizing" and intensifying its timeless surface.

The jury highly appreciated the simple elegance and the refined expressive qualities of the project. It was praised for its functional clarity, poetic statement and delicate and discrete approach to the site and to the architectural program. Moreover, the layout of the exhibition galleries is aligned in a way that allows it to cover the visual lines to the Pyramids 
through a prism of light. The museum is situated at the intersection of two cones of vision, one is directed towards the pyramids and the other is directed towards the city of Cairo. Accordingly, the design pays special attention to the physical solution for the proposed pedestrian way to the Pyramids plateau. A strong iconic power was maintained in spite of the delicacy and technical sophistication of the translucent stonewall. Thus, again, the main goal for implementing this selected project was to enhance form over function as a way for promoting the project as well as the renovations and developments to the whole site.

However, many political and financial problems were associated with the delay in the completion of the project, especially after the revolution in 2011, which changed the political agenda in Egypt totally. Accordingly, the complete analysis associated with the project can be re-implemented after its opening to evaluate the iconic city effect it offers.

\subsection{National Museum for Egyptian Civilization:}

The first museum of civilization in Egypt, the "NMEC" is located on the archaeological site of El-Fustat in Old Cairo, overlooking Ain El-Seera Lake. The Museum was designed by Egyptian architect El Ghazzali Kesseiba. The exhibition spaces are being designed by Japanese architect Arata Isozaki. The "NMEC" is aspired to showcase Egyptian civilization from prehistoric times to the present day, using a multidisciplinary approach that highlights the country's tangible and intangible heritage.

It has to be taken into consideration that civilization museums differ from archeological museums in their nature and objectives. Archeological museums are assigned to a certain period of time without being related to a previous or succeeding periods to it. The objective in such museums is mainly to present and highlight the artistic value of the displayed artifacts. This is not the case in this case study, in which the architect had to deal conceptually with different layers of civilizations in Egypt, and represent them within a setting of architecture which helps to provide an added value humbly and doesn't interfere with the display. Thus, in this project, function was intended to overcome form to help in the continuation of the architectural concept over various decades.

As Abdel Moneim (2005) explains, the site is visually connected to all historical urban sites of Greater Cairo. It is the meeting point of many cultures. In the south, the Helwan and Al Ma'aadi cultures represent the prehistoric period in Egypt. In the far west, the Saqqara pyramid and the Giza pyramids symbolize the Pharaonic period. In the near west, stand the Babylon castle from the Roman period and churches from the Coptic period. Islamic historic Cairo in the north and the nineteenth century Mohammad Ali Citadel in the north-east complete the cultural and visual landscape of Egypt up until modern times. The site also includes a rare natural lake, Ain Al Seera.

The composition of the museum adopted a series of exhibitions, (fig. 3), (fig. 4). The Core Exhibition will highlight the main achievements of Egyptian civilization in a chronological approach featuring eight main time periods: Prehistory, Archaic, Pharaonic, Graeco-Roman, Coptic, Islamic, Modern, and Contemporary. The Thematic Galleries are organized according to six themes: Dawn of civilization, The Nile, Writing, State and Society, Material Culture, Beliefs and Thinking. Finally, the Royal Mummies Gallery containing the remains of great pharaohs will be the climax of the museum and will recreate the experience of visiting one of the Royal tombs in the Valley of the Kings.

The main concept which the architect presented was to offer timeless architecture to embody the different layers of history and civilization in Egypt. Thus, no iconic was targeted, but rather a minimalistic statement to allow for the intermingling of the different layers of history. As a matter of fact, the success of the functional setting, the clarity of the display as well as the strength of the architectural meaning were the main reason for the selection of the project in the competition which took place in the 1980s. The timeless architecture aimed to be presented by the architect played a strong role in the validity of the design in spite of the excessive delay which took place on the implementation due to political problems. However, this is a two-fold problem, since the lack of the creation of a strong iconic image was one of the reasons behind the delay of the completion of the museum construction.

\section{Conclusion}

The paper presented how the debate regarding form and function can be re-interpreted in the shadows of globalization and iconic city effect. This association between the two concepts was highlighted in the analysis of the case studies focusing on major state-led architectural projects in Egypt to represent how the creation of the icon played an important role in those projects, leading to the use of architectural form itself as a new function for buildings. 


\section{References}

[1] Abdel Moneim, A. (2005).The National Museum of Egyptian Civilization, Museum International, Blackwell Publishing, Vol. 57, No. 1-2.

[2] Abdel Raaouf, A. (2001). Contemporary Egyptian Architecture, Critical Issues and Innovative Trends, Al Benaa, $128, \mathrm{KSA},(\mathrm{p} .28)$.

[3] Adam, R. (2008) Globalisation and architecture: The challenges of globalisation are relentlessly shaping architecture's relationship with society and culture. The Architectural Review , 223, 1332, (pp. 74-77).

[4] Amin, G. (2012), Whatever Happened to the Egyptian Revolution? Dar Al-Shorouk, (pp. 50-51).

[5] Asfour, K., (2003). The GEM and the Egyptian architects—bad luck? The Architectural Review, UK

[6] Cruz, C. (2012). Wright's Organic Architecture: From "Form Follows Function" to "Form and Function are One", Wolkenkuckucksheim, 32, pp. 27-36.

[7] Farhat, A. M., (1990). Evaluating the Winning Project in the Alexandria Library Competition, Ala'm El Benaa, 109, Egypt, (pp.23-29).

[8] Frampton, K. (1991). In Jones, P. (2009), Putting Architecture in its Social Place: A Cultural Political Economy of Architecture, Urban Studies, 46, (p.2527).

[9] Ibrahim, A. B. (1989). Lessons from New Alexandrina Library, Ala'm El Benaa, 105, Egypt, (pp.8-12).

[10] McNeill, D. (2000). McGuggenisation? National identity and globalisation in the Basque country. Political Geography, 19, 4, (pp. 473-494).

[11] Mettam, G. R., \& Adams, L. B. (1994). How to prepare an electronic version of your article. In B. S. Jones, \& R. Z. Smith (Eds.), Introduction to the electronic age (pp. 281-304). New York: E-Publishing Inc.

[12] Raof, S. (2001). Ecohouse: A Design Guide. Oxford. Architectural Press.

[13] Ren, X. (2008), Architecture And Nation Building In The Age Of Globalization: Construction Of The National Stadium Of Beijing For The 2008 Olympics, Journal Of Urban Affairs, 30, 2.

[14] Sklair, L. (2006). Iconic Architecture and Capitalist Globalization, City, 10, Routldge.

[15] Strom, E. (2002). Converting pork into porcelain: Cultural institutions and downtown development. Urban Affairs Review, 38, 1, (pp. 3-21).

[16] Strunk, W., Jr., \& White, E. B. (1979). The elements of style (3rd ed.). New York: Macmillan.

[17] Van der Geer, J., Hanraads, J. A. J., \& Lupton, R. A. (2000). The art of writing a scientific article. Journal of Scientific Communications, 163, 51 - 59.

Figures:

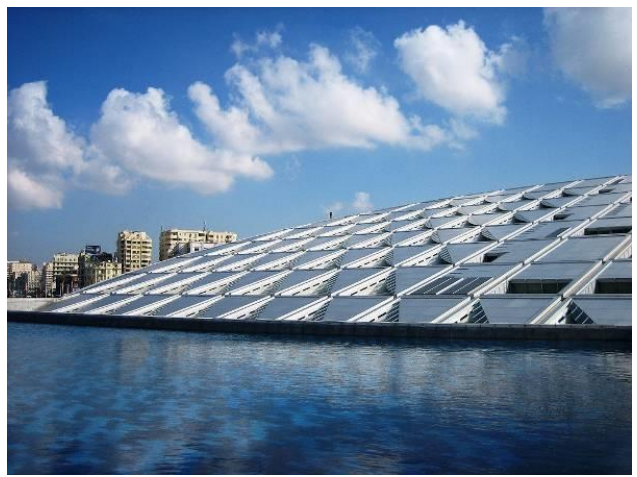

Figure 1: Alexandria Bibotheque by Snohetta. 


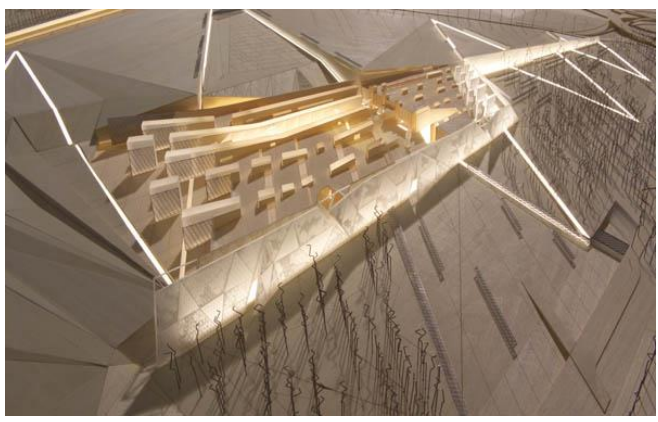

Fig. 2 - GEM Winning Competition Entry.

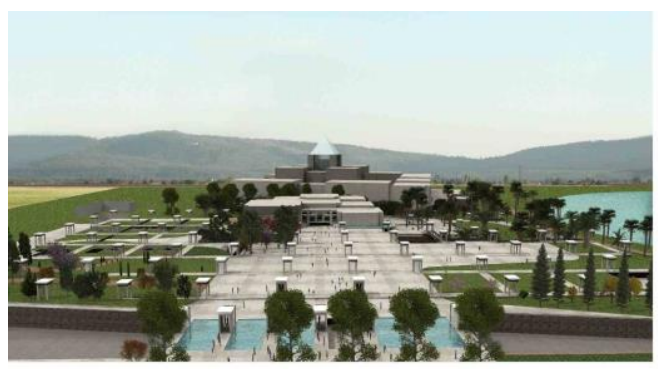

Fig. 3 - NMEC, Overall View

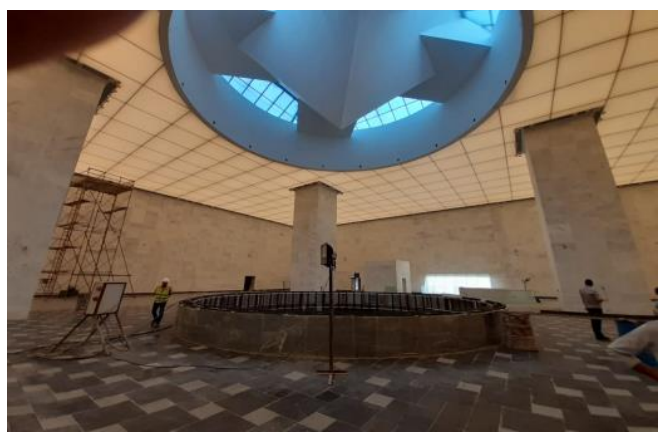

Fig. 4 - NMEC, Current Construction Phase 